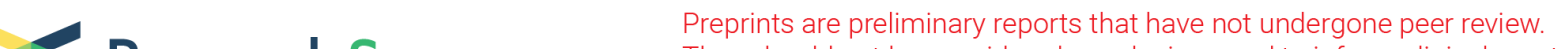 $\begin{array}{ll}\text { Research Square } & \text { They should not be considered conclusive, used to inform clinical practice, } \\ \text { or referenced by the media as validated information. }\end{array}$
}

\section{Overuse of Follow-up Chest Computed Tomography in Patients With Incidentally Identified Nodules Suspicious for Lung Cancer}

\section{Ran Guo}

Fudan University Shanghai Cancer Center

\section{Yang Zhang}

Fudan University Shanghai Cancer Center

\section{Zelin Ma}

Fudan University Shanghai Cancer Center

\section{Chaoqiang Deng}

Fudan University Shanghai Cancer Center

\section{Fangqiu Fu}

Fudan University Shanghai Cancer Center

\section{Hong Hu}

Fudan University Shanghai Cancer Center

\section{Yihua Sun}

Fudan University Shanghai Cancer Center

Haiquan Chen ( $\nabla$ hqchen1@yahoo.com )

Fudan University Shanghai Cancer Center https://orcid.org/0000-0002-1305-971X

\section{Research Article}

Keywords: Non-small cell lung cancer, lung cancer screening, Safety, Chest CT

Posted Date: March 16th, 2021

DOI: https://doi.org/10.21203/rs.3.rs-259864/v1

License: (c) (1) This work is licensed under a Creative Commons Attribution 4.0 International License. Read Full License

Version of Record: A version of this preprint was published at Journal of Cancer Research and Clinical Oncology on July 8th, 2021. See the published version at https://doi.org/10.1007/s00432-021-03692-6. 


\section{Abstract}

Purpose: Regardless of professional societies agreed that CT screening inconsistent with recommendation leads to radiation-related cancer and unexpected cost, many patients undergo unnecessary chest CT before treatment. The goal of this study was to assess the overuse of Chest CT in different type of patients.

Methods: Data on 1853 patients who underwent pulmonary resection from May 2019 to May 2020 were retrospectively analyzed. Data collected include age, sex, follow-up time, density and size of nodules and frequency of undergoing Chest CT. Pearson $\chi 2$ test and logistic regression were conducted to compare the receipt of CT screening.

Results: Among 1853 patients in the study, 689 (37.2\%) had overused Chest CT during follow-up of the lung cancer. This rate was $16.2 \%$ among patients with solid nodules, $57.5 \%$ among patients with pure ground glass opacity (pGGO), and $41.4 \%$ among patients with mixed ground glass opacity (mGGO) $(P<.001) .50 .7 \%$ in the "age $\leq 40$ " group, $39.8 \%$ in the " $41 \leq$ age $\leq 50$ " group, $38.7 \%$ in the " $51 \leq$ age $\leq 60$ " group, $32.3 \%$ in the "61 $\leq$ age $\leq 70$ " group, $27.8 \%$ in the " $>70$ " group underwent unnecessary CT $(\mathrm{P}<.001)$. Female get more unnecessary CT than male $(40.6 \%$ vs $32.8 \%, P<.001)$. Factors associated with a greater likelihood of Chest CT is the density of nodules (odds ratios [ORs] of 0.53 for mGGO; 0.15 for solid nodule, $\mathrm{P}<.0001$, vs patients with $\mathrm{pGGO}$ ).

Conclusion: roughly $37 \%$ patients with pulmonary nodules received Chest CT too frequently despite national recommendations against the practice. Closer adherence to clinical guidelines is likely to result in more cost-effective care.

\section{Introduction}

Lung cancer is the leading cause of cancer death worldwide, with an estimated 1.6 million deaths annually. ${ }^{1}$ Since a high range of lung cancer occurs and develops without any symptom until end-stage, screening becomes significant method of spotting lung cancer. As the US National Lung Screening Trial (NLST), Nederlands-Leuvens Longkanker Screenings Onderzoek (NELSON) and other trial revealed that Computed Tomography (CT) can produce more effect compared with X-ray, Chest CT becomes the first choice of lung cancer screening. ${ }^{2-5}$

However, CT is not a perfect choice for lung cancer screening. According to John Brodersen, $49 \%$ of detected cancers by Low-dose CT (LDCT) may be overdiagnosed, ${ }^{6-7}$ and researchers also mentioned that risk of radiation-induced cancers can be a potentially harmful effect of Chest CT which is cumulative over a lifetime. ${ }^{2,8-11}$. Another concern is the cost-effectiveness of the Chest CT. The NLST results suggested that screening with low-dose CT cost $\$ 100,000$ per QALY gained, but study of William C. Black showed that screening conducted outside the trial may be costlier if patients' counseling and follow-up are 
properly accounted for the price. ${ }^{2,12}$ The cost could become more considerable if the number of unnecessary CT scans increase, making a heavy burden for patients and economy of healthcare.

To minimize the risk of radiation and unnecessary cost, multiple specialty societies have issued recommendations against Chest CT for patients with suspicious pulmonary nodules. ${ }^{13-15}$ Although specific recommendations differ somewhat, all societies agreed that CT screening is not an examination which can be experienced without limitation. But even with these numerous guidelines and recommendations, overuse of Chest CT is routinely performed in patients with nodule suspicious for pulmonary tumor. The goal of this study was to assess the use of Chest CT in patients with pulmonary nodules, and identify the demographic and clinical factors associated with receipt of Chest CT.

\section{Materials And Methods}

\section{Patients and samples}

From May 2019 to May 2020, we consecutively procured data of lung cancer patients who underwent pulmonary resection in the Department of Thoracic Surgery, Fudan University Shanghai Cancer Center, Shanghai, China. The frequency of CT screening is collected by telephone follow-up and checking medical history. Subjects eligible for this study had to meet the following criteria: complete follow-up history and clinical data. Patients who received neoadjuvant chemotherapy were excluded from the study because of inconsistencies of the reason they get Chest CT. Patients with a recurrent lung cancer, with multiple concurrent cancers, and with former other malignancies were also excluded from the study. Patients who underwent Chest CT because of symptoms related to lung cancer were excluded since the NCCN guideline cannot apply to them. This research was approved by the Institutional Review Board of the Fudan University Shanghai Cancer Center, Shanghai, China. Written informed consent was obtained from all patients.

As different patients need different strategies of CT screening, we used the guideline of NCCN which gave the advice for patients who incidentally found nodules suspicious for lung cancer, ${ }^{13}$ and then grouped them into two groups: abiding by the guideline or not.

\section{Statistical Analysis}

All the statistical analyses were performed in the SPSS for Windows (Version 16.0, Chicago, IL). We assessed the baseline characteristics of patients included in our sample, grouped them by following the guideline or not. Age, sex, density and size of nodules are modeled as categorical variables. Variables were reported as counts and percentages, and groups were compared using chi-square tests for significance. We used the Pearson $\chi 2$ test to compare the lung cancer detection rate. Finally, we performed a multivariable logistic regression for the likelihood of overusing Chest CT for staging. Pvalues were two-tailed for all the tests. Statistical significance was set as $p<0.05$. 


\section{Results}

Among 2667 patients with nodules suspicious for lung cancer, a total of 1853 patients met inclusion criteria (Figure 1). All patients were Chinese. Baseline demographic and clinical characteristics of the cohort are summarized in Table 1.

\begin{tabular}{|c|c|c|c|c|}
\hline variable & $\begin{array}{l}\text { Overall Cohort } \\
\mathrm{n}(\%)\end{array}$ & $\begin{array}{l}\text { Not abiding by the guildline } \\
\mathrm{n}(\%)\end{array}$ & $\begin{array}{l}\text { abiding by the guildline } \\
\mathrm{n}(\%)\end{array}$ & $P$ value \\
\hline Total, $n$ & $1853(100)$ & 689 (37.2) & 1164(62.8) & \\
\hline Sex & & & & $<0.001$ \\
\hline Male & $816(44.0)$ & $268(32.8)$ & $548(67.2)$ & \\
\hline Female & $1037(56.0)$ & $421(40.6)$ & 618 (59.4) & \\
\hline Age, y & & & & $<0.001$ \\
\hline$\leq 40$ & $209(11.3)$ & $106(50.7)$ & $103(49,3)$ & \\
\hline $41 \otimes 50$ & $324(17.5)$ & $129(39.8)$ & $195(60.2)$ & \\
\hline $51 \rrbracket 60$ & $561(30.3)$ & 217 (38.7) & $344(61.3)$ & \\
\hline $61 \otimes 70$ & $572(30.9)$ & $185(32.3)$ & 387 (67.7) & \\
\hline$>70$ & $187(10.1)$ & $52(27.8)$ & 135 (72.2) & \\
\hline Nodule density & & & & $<0.001$ \\
\hline pGGO & $478(25.8)$ & 275 (57.5】 & $203(42.5)$ & \\
\hline $\mathrm{mGGO}$ & 759 (40.9) & 314 (41.4) & $445(58.6)$ & \\
\hline Solid nodule & 616(33.2) & 100 (16.2) & $516(83.8)$ & \\
\hline
\end{tabular}

Abbreviations:

pGGO: pure ground glass opacity.

mGGO: mixed ground glass opacity.

*Bold indicates statistically significant $P$ values $(P<0.05)$

Overall, during the 12-months study period, around $37.2 \%$ of our patients underwent excessive CT. The proportion of females was $56.0 \% .40 .6 \%$ of them ignored the recommendation, while this rate changed to $32.8 \%$ among males. The percentage of patients $\leq 40$ years, 41 to 50 years, 51 to 60 years, 61 to 70 years 
and $>70$ years were $11.3 \%, 17.5 \%, 30.3 \%, 30.9 \%$ and $10.1 \%$, and $50.7 \%, 39.8 \%, 38.7 \%, 32,3 \%, 27.8 \%$ of them received unnecessary examination.

As for density of nodules, $25.8 \%$ found pure ground glass opacity(pGGO), $40.9 \%$ found mixed ground glass opacity (mGGO), and $32.2 \%$ found solid nodules during their screening. $57.5 \%, 41.4 \%$, and $16.2 \%$ of them did not abide by the guideline of NCCN.

\begin{tabular}{|c|c|c|c|c|}
\hline variable & $\begin{array}{l}\text { Overall Cohort } \\
\mathrm{n}(\%)\end{array}$ & $\begin{array}{l}\text { Not abiding by the guildline } \\
\mathrm{n}(\%)\end{array}$ & $\begin{array}{l}\text { abiding by the guildline } \\
\mathrm{n}(\%)\end{array}$ & $P$ value* \\
\hline pGGO & & & & $<0.001$ \\
\hline 0 & 167 (34.9) & $93(55.7)$ & $74(44.3)$ & \\
\hline 1 & $243(50.8)$ & 125 (51.4) & 118 (48.6) & \\
\hline 2 & $48(10.0)$ & 39 (81.3) & $9(18.8)$ & \\
\hline 3 & $11(2.3)$ & $10(90.9)$ & $1(9.1)$ & \\
\hline$>3$ & $9(1.9)$ & $8(88.9)$ & $1(10.1)$ & \\
\hline mGGO & & & & $<0.001$ \\
\hline 0 & 295 (37.3) & 144 (50.9) & $139(49.1)$ & \\
\hline 1 & 274 (33.9) & $62(24.1)$ & 195 (75.9) & \\
\hline 2 & $84(10.9)$ & $49(59.0)$ & $34(41.0)$ & \\
\hline 3 & $71(9.4)$ & $29(40.8)$ & $42(59.2)$ & \\
\hline$>3$ & $65(8.6)$ & $30(46.2)$ & $35(53.8)$ & \\
\hline \multicolumn{2}{|c|}{ Solid nodule } & & & $<0.001$ \\
\hline 0 & $440(56.6)$ & $39(11.2)$ & $310(88.8)$ & \\
\hline 1 & $182(22.1)$ & $16(11.8)$ & $120(88.2)$ & \\
\hline$>1$ & $152(21.3)$ & $45(34.4)$ & $86(65.6)$ & \\
\hline
\end{tabular}

Abbreviations:

pGGO: pure ground glass opacity.

mGGO: mixed ground glass opacity.

*Bold indicates statistically significant $P$ values $(P<0.05)$ 
Since different density of nodules need different screening strategies, we grouped patients by their density of nodules and assessed how many patients who need different follow-up time were inconsistent with NCCN (Table 2). As a result, for patients with pGGO, 55.7\% of patients who need 0 follow-up violated the recommendation, and this rate ranged into $51.4 \%, 81.3 \%, 90.9 \%, 88.9 \%$ for who need $1,2,3$ and more than 3 follow-ups. As for patients with mGGO, 50.9\%, 24.1\%, 59.0\%, 40.8\%, 46.2\% patients who need 0, 1 , 2,3 and more than 3 follow-ups were not adhere to the guideline, and $11.2 \%, 11.8 \%, 34.4 \%$ patients with solid nodules who need 0, 1, 2 follow-ups underwent unnecessary Chest CT for screening.

In univariable analysis, factors associated with greater use of CT included younger age (odds ratios [ORs] of 0.64 for $41-50$ years, $P=.014 ; 0.62$ for $51-60$ years, $P=.003 ; 0.47$ for $61-70$ years, $P<.001$; and 0.37 for $\geq 71$ years, $P<.0001 ;$ vs $\leq 40$ years), female sex (OR, 1.40; $P<.001)$ and lower nodule density(ORs of 0.52 for $\mathrm{mGGO}, \mathrm{P}<.001 ; 0.14$ for solid nodule, $\mathrm{P}<.001$ )(Table 3 ). In terms of the following-up time, patients tended to abide by the guideline when the first follow-up was recommended (ORs of 0.84 for patients with pure GGO, $P=.040 ; 0.30$ for $m G G O, P<.001$ ).

Correlations among patients' unnecessary CT scan with clinical features were further evaluated by multivariable analysis using logistic regression analysis (Table 4). The result suggested that density of the nodules were independent predictors of overusing Chest CT (ORs of 0.53 for $\mathrm{mGGO}, \mathrm{P}<.0001 ; 0.15$ for solid nodule, $\mathrm{P}<.0001$, vs patients with $\mathrm{pGGO}$ ). 


\begin{tabular}{|c|c|c|}
\hline Characteristic & OR & $P$ value ${ }^{*}$ \\
\hline \multicolumn{3}{|l|}{ Age, y } \\
\hline$\leq 40$ & Ref & \\
\hline $41 \otimes 50$ & $0.64(0.45-0.91)$ & 0.014 \\
\hline $51 \rrbracket 60$ & $0.62(0.45-0.85)$ & 0.003 \\
\hline $61 \otimes 70$ & $0.47(0.34-0.64)$ & $<0.001$ \\
\hline$\geq 71$ & $0.37(0.25-0.57)$ & $<0.001$ \\
\hline \multicolumn{3}{|l|}{ Sex } \\
\hline Male & Ref & \\
\hline Female & $1.40(1.15-1.70)$ & $<0.001$ \\
\hline \multicolumn{3}{|l|}{ Nodule density } \\
\hline pGGO & Ref & \\
\hline mGGO & $0.52(0.41-0.65)$ & $<0.001$ \\
\hline Solid nodule & $0.14(0.11-0.19)$ & $<0.001$ \\
\hline \multicolumn{3}{|c|}{ Required following-up times for different density of nodule } \\
\hline \multicolumn{3}{|l|}{ pGGO } \\
\hline 0 & Ref & \\
\hline 1 & $0.84(0.39-0.91)$ & 0.40 \\
\hline 2 & $3.45(2.27-8.63)$ & 0.002 \\
\hline 3 & $7.96(1.82-21.82)$ & 0.050 \\
\hline$>3$ & 6..37(0.78-52.04) & 0.084 \\
\hline \multicolumn{3}{|l|}{ mGGO } \\
\hline 0 & Ref & \\
\hline 1 & $0.30(0.21-0.44)$ & $<0.001$ \\
\hline 2 & $1.39(0.85-2.28)$ & 0.192 \\
\hline 3 & $0.67(0.39-1.13)$ & 0.132 \\
\hline$>3$ & $0.83(0.48-1.42)$ & 0.492 \\
\hline Solid nodule & & \\
\hline
\end{tabular}




\begin{tabular}{|lll|}
0 & Ref & \\
1 & $1.12(0.61-2.07)$ & 0.70 \\
$>1$ & $4.16(2.55-6.80)$ & $<0.001$ \\
\hline
\end{tabular}

Abbreviations:

OR: odds ratio.

pGGO: pure ground glass opacity.

mGGO: mixed ground glass opacity.

*Bold indicates statistically significant $P$ values $(P<0.05)$

\begin{tabular}{|lll|}
\hline \multicolumn{3}{|l|}{ Table 4. Multivariable analysis of Associations with Chest CT } \\
\hline Characteristic & OR & P value $^{*}$ \\
\hline Age, y & & \\
\hline & & 0.320 \\
\hline $51 \varangle 50$ & $0.83(0.57-1.20)$ & 0.658 \\
$61 \varangle 60$ & $0.93(0.66-1.31)$ & 0.318 \\
$\geq 71$ & $0.83(0.59-1.19)$ & 0.328 \\
\hline Sex & $0.80(0.50-1.26)$ & 0.941 \\
\hline Female & $0.99(0.81-1.22)$ & $<0.001$ \\
\hline Nodule density & & $<0.001$ \\
\hline mGGO & $0.53(0.42-0.68)$ & \\
\hline Solid nodule & $0.15(0.11-0.20)$ & \\
\hline
\end{tabular}

Abbreviations:

OR: odds ratio.

mGGO: mixed ground glass opacity.

*Bold indicates statistically significant $P$ values $(P<0.05)$

\section{Discussion}


Despite the mention of risk about overuse of Chest CT by specialty societies, patients were still willing to get the examination as many as possible. In this retrospective cohort study, we found that almost 1 in 3 patients received unnecessary lung cancer screening, and the rate dramatically varied by different characteristics. Previous study suggested the disadvantage of unnecessary Chest $\mathrm{CT}$, and there were studies about overuse of Chest CT in patients with breast cancer or studies about lung cancer screening inconsistent with USPSTF, ${ }^{16-18}$ but to our knowledge, this is the first study to assess the overuse of Chest CT during follow-up after finding nodules suspicious for lung cancer.

Our study finally showed that overuse of CT is likely to happen in patients with less density, and patients with pGGO most tend to undergo CT scan which is inconsistent with recommendation. As a fact, there is no perfect method to distinguish malignant and benign GGO with accurate certainty. A period of followup may be helpful for diagnosis, but the interval of follow-up can be longer than 1 year. Lee et al reported that pure GGO lesions $\leq 10 \mathrm{~mm}$ have a volume-doubling time of more than 400 days, and a study from Japan also suggested that the optimal observation period for patients with multiple GGOs is 36 months. 19-20 NCCN guidelines recommended that both $\mathrm{pGGO}$ and $\mathrm{mGGO}<6 \mathrm{~mm}$ do not require any follow up and that pure GGOs $\geq 6 \mathrm{~mm}$ should be followed every 2 years, for up to 5 years. ${ }^{13}$

But since a percentage of GGNs disappear spontaneously in short term, ${ }^{21}$ some medical workers routinely ask patients to get examination again in 3 months after they found pulmonary opacities to check if the GGO is only an inflammation, leading to a potential risk of overusing CT scan. Another study of Lee et al suggested that 2 of 90 GGNs (2.2\%) followed up for more than 4 years showed significant growth after 4 years, and whether patients need Chest CT after 5 years follow-up still remains a problem. 22 These can be reasons for undergoing Chest CT without complying with the recommendation.

Female and younger patients also showed higher rate of inconsistence with NCCN, but this factor may not be the true influencer of unnecessary Chest CT as percentage of GGO is also higher among these groups in our study. $30.8 \%$ of females found pGGO during their Chest CT screening, whereas only $14.8 \%$ of males found pGGO nodules. This result is in line with those reported by Huang et al. ${ }^{23}$ Their study revealed that PGGO is associated with females, and although there is not significance difference, younger age patients get more pGGO in the research.

Given that our analysis relied on data of Fudan University Shanghai Cancer Center and telephone following-up, there are some incumbent limitations to consider. Prior studies have already revealed significant geographic variation about screening and therapy protocol in clinical practice. ${ }^{24-25} \mathrm{~A}$ certain level of recalling bias should be acknowledged, and furthermore, our conclusions only apply to the population analyzed - patients who got pulmonary resection in Fudan University Shanghai Cancer Center. We also excluded patients who had history of other malignant tumors or neoadjuvant therapy, which can lead to selection bias. These patients usually have more advanced disease, and were more likely to get examination for accurate diagnosis, but the purpose of CT for them could be evaluating the therapeutic effect instead of screening, so their examination history shouldn't be judged by the guideline. 
It would be interest to evaluate the variations among different area and hospitals, and further research in this aspect is warranted.

\section{Conclusion}

This retrospective analysis of the data suggests overuse of unnecessary Chest CT in patients with lung nodules suspicious for lung cancer, and this rate vary by radiologic density of the nodules. This dissimilarity may stem from clinical uncertainty, general lack of familiarity with national recommendations and patients' anxious about tumor. Efforts to disseminate evidence-based best practices and adherence to the guidelines will not only spare patients' unnecessary radiation, also curb excessive spending.

\section{Declarations}

Funding: This work was supported by the National Natural Science Foundation of China (81930073), Shanghai Science and Technology Innovation Action Project (20JC1417200), Shanghai Municipal Science and Technology Major Project (2017SHZDZX01, VBH1323001/026), Shanghai Municipal Key Clinical Specialty Project (SHSLCZDZK02104), and Pilot Project of Fudan University (IDF159045).

Conflicts of interest/Competing interests: We declare that there is no professional or other personal interest of any nature or kind in any product

Availability of data and material: all data and material is applicable.

Code availability: we used SPSS to analyze our data, and the software is applicable.

Ethics approval: This research was approved by the Institutional Review Board of the Fudan University Shanghai Cancer Center, Shanghai, China.

Consent to participate: Written informed consent was obtained from all patients.

Consent for publication: Written informed consent for publication was obtained from all patients.

\section{Acknowledgements}

This work was supported by the National Natural Science Foundation of China (81930073), Shanghai Science and Technology Innovation Action Project (20JC1417200), Shanghai Municipal Science and Technology Major Project (2017SHZDZX01, VBH1323001/026), Shanghai Municipal Key Clinical Specialty Project (SHSLCZDZK02104), and Pilot Project of Fudan University (IDF159045).

\section{References}


1. International Agency for Research on Cancer, World Health Organization. Lung cancer. In: GLOBOCAN 2012: estimated cancer incidence, mortality and prevalence worldwide in 2012. Lyon, France: International Agency for Research on Cancer, World Health Organization; 2013

2. National Lung Screening Trial Research Team, Aberle DR, Adams AM, et al. Reduced lung-cancer mortality with low-dose computed tomographic screening. N Engl J Med. 2011;365(5):395-409. doi:10.1056/NEJMoa1102873

3. Yousaf-Khan U, van der Aalst C, de Jong PA, et al. Risk stratification based on screening history: the NELSON lung cancer screening study. Thorax. 2017;72(9):819-824. doi:10.1136/thoraxjnl-2016209892

4. Pastorino U, Sverzellati N, Sestini S, et al. Ten-year results of the Multicentric Italian Lung Detection trial demonstrate the safety and efficacy of biennial lung cancer screening. Eur $\mathrm{J}$ Cancer. 2019;118:142-148. doi:10.1016/j.ejca.2019.06.009

5. de Koning HJ, van der Aalst CM, de Jong PA, et al. Reduced Lung-Cancer Mortality with Volume CT Screening in a Randomized Trial. N Engl J Med. 2020;382(6):503-513. doi:10.1056/NEJMoa1911793

6. van der Aalst CM, Ten Haaf K, de Koning HJ. Lung cancer screening: latest developments and unanswered questions. Lancet Respir Med. 2016;4(9):749-761. doi:10.1016/S2213-2600(16)30200-4

7. Brodersen J, Voss T, Martiny F, Siersma V, Barratt A, Heleno B. Overdiagnosis of lung cancer with lowdose computed tomography screening: meta-analysis of the randomised clinical trials. Breathe (Sheff). 2020 Mar;16(1):200013. doi: 10.1183/20734735.0013-2020. PMID: 32194774; PMCID: PMC7078745.

8. Bach PB, Mirkin JN, Oliver TK, et al. Benefits and harms of CT screening for lung cancer: a systematic review [published correction appears in JAMA. 2012 Oct 3;308(13):1324] [published correction appears in JAMA. 2013 Jun 5;309(21):2212]. JAMA. 2012;307(22):2418-2429. doi:10.1001/jama.2012.5521

9. Rampinelli C, De Marco P, Origgi D, et al. Exposure to low dose computed tomography for lung cancer screening and risk of cancer: secondary analysis of trial data and risk-benefit analysis. BMJ. 2017;356:j347. Published 2017 Feb 8. doi:10.1136/bmj.j347

10. Kalra MK, Maher MM, Rizzo S, Kanarek D, Shepard JA. Radiation exposure from chest CT: issues and strategies [published correction appears in J Korean Med Sci. 2004 Jun;19(3):487. Shephard JA [corrected to Shepard JA]]. J Korean Med Sci. 2004;19(2):159-166. doi:10.3346/jkms.2004.19.2.159

11. Board on Radiation Effects Research, Division on Earth and Life Studies, National Research Council of the National Academies. Health risks from exposure to low levels of ionizing radiation. BEIR VII, Phase 2. Washington, DC: National Academies Press; 2005.

12. Black WC, Gareen IF, Soneji SS, et al. Cost-effectiveness of CT screening in the National Lung Screening Trial. N Engl J Med. 2014;371(19):1793-1802. doi:10.1056/NEJMoa1312547

13. Ettinger DS, Argiris A, Bepler G. NCCN Clinical Practice Guidelines in Oncology: Non-Small Cell Lung Cancer. Version 1.2004. Obtained with permission from NCCN February 2, 2019. To view the most recent version, visit org. 
14. Kazerooni EA, Armstrong MR, Amorosa JK, et al. ACR CT accreditation program and the lung cancer screening program designation. J Am Coll Radiol. 2015;12(1):38-42. doi:10.1016/j.jacr.2014.10.002

15. Wender R, Fontham ET, Barrera E Jr, et al. American Cancer Society lung cancer screening guidelines. CA Cancer J Clin. 2013;63(2):107-117. doi:10.3322/caac.21172

16. Dull B, Linkugel A, Margenthaler JA, Cyr AE. Overuse of Chest CT in Patients With Stage I and II Breast Cancer: An Opportunity to Increase Guidelines Compliance at an NCCN Member Institution. J Natl Compr Canc Netw. 2017;15(6):783-789. doi:10.6004/jnccn.2017.0104

17. Richards TB, Doria-Rose VP, Soman A, et al. Lung Cancer Screening Inconsistent With U.S. Preventive Services Task Force Recommendations. Am J Prev Med. 2019;56(1):66-73. doi:10.1016/j.amepre.2018.07.030

18. Farjah F, Monsell SE, Gould MK, et al. Association of the Intensity of Diagnostic Evaluation With Outcomes in Incidentally Detected Lung Nodules [published online ahead of print, 2021 Jan 19]. JAMA Intern Med. 2021;e208250. doi:10.1001/jamainternmed.2020.8250.

19. Sato Y, Fujimoto D, Morimoto T, et al. Natural history and clinical characteristics of multiple pulmonary nodules with ground glass opacity. Respirology. 2017;22(8):1615-1621. doi:10.1111/resp.13089

20. Oh JY, Kwon SY, Yoon HI, et al. Clinical significance of a solitary ground-glass opacity (GGO) lesion of the lung detected by chest CT. Lung Cancer. 2007;55(1):67-73. doi:10.1016/j.lungcan.2006.09.009

21. Lee SW, Leem CS, Kim TJ, et al. The long-term course of ground-glass opacities detected on thinsection computed tomography. Respir Med. 2013;107(6):904-910. doi:10.1016/j.rmed.2013.02.014

22. Huang $C$, Wang $C$, Wang $Y$, et al. The Prognostic Significance of Pure Ground Glass Opacities in Lung Cancer Computed Tomographic Images. J Cancer. 2019;10(27):6888-6895. Published 2019 Nov 17. doi:10.7150/jca.33132

23. Balekian AA, Fisher JM, Gould MK. Brain Imaging for Staging of Patients With Clinical Stage IA Nonsmall Cell Lung Cancer in the National Lung Screening Trial: Adherence With Recommendations From the Choosing Wisely Campaign. Chest. 2016;149(4):943-950. doi:10.1378/chest.15-1140

24. Milligan MG, Cronin AM, Colson Y, et al. Overuse of Diagnostic Brain Imaging Among Patients With Stage IA Non-Small Cell Lung Cancer. J Natl Compr Canc Netw. 2020;18(5):547-554. doi:10.6004/jnccn.2019.7384

\section{Figures}


Patients who underwent pulmonary resection from May 2019 to April $2020(n=2667)$

Had neoadjuvant therapy $(n=54)$

Previous tumor history $(\mathrm{n}=487)$

Found pulmonary nodules incidentally $(n=2126)$

Never have had neoadjuvant therapy $(n=2613)$

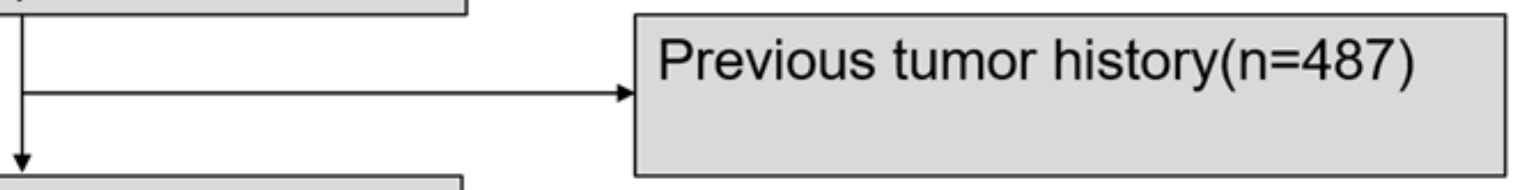

\section{Never had surgical history of} lung cancer $(n=1930)$

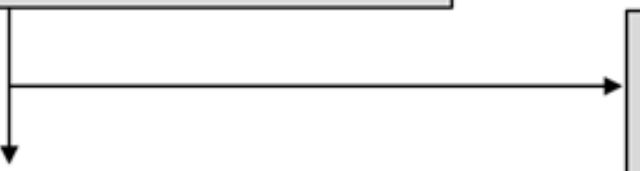

Found pulmonary nodules

nonincidentally $(n=196)$

Loss of follow-up or data incompleted $(n=77)$

Completed and reliable data $(n=1853)$

Figure 1

Study Cohort 